\title{
The Research on the Interactive Interface Design in Self-express Service System(SESS)
}

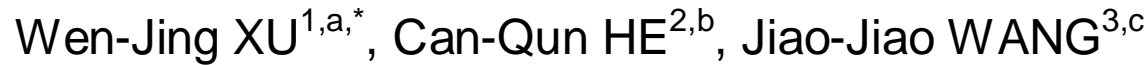 \\ ${ }^{1}$ Art School of Jiangsu University,Zhenjiang Jiangsu,China212013 \\ ${ }^{2}$ Changzhou Campus Of Hohai University, Changzhou Jiangsu,China213000 \\ ${ }^{3}$ Art School of Jiangsu University,Zhenjiang Jiangsu,China212013 \\ a519044134@qq.com, b42446028@qq.com, c1041032241@qq.com
}

Keywords: Self-service, Express, Interface design, Interaction design

\begin{abstract}
With the development of online shopping,higher delivery efficiency has been required. Combined with the"Self-express Service System Design based on University City",the paper expresses the self-express service system design from the concept,development,the interactive interface design and the significance of self-express service system. Through deep analysis of the express industry situation,users' need,application environment,design concept,operation process and interface design,it shows the simple and convenient operating interface and the effect of self-express service system, which aims at exploring a new self-express service mode. It is innovation for express development and will benefit people's life with great convenience.
\end{abstract}

\section{Introduction}

With the rapid development of online shopping, it has become an important part of our daily life, which can also promote the development of the express industry. For the expansion of user groups and business ,the express industry has to be faced with many problems like service efficiency.In fact,many other industries such as banking services have experienced the same problems and then choose self-service to solve the problems. Therefore it has been used more widely.Based on the need of express industry development and the great advantage of self-service,we believe that self-express will be the general trend. However,for the lack of guidance,the users are often worried about the control and operation failure of self-service, which may make them feel depressed and frustrated. To make the SSES get a good user experience,more detailed study on the interactive interface design should be done to enhance the usability of system.

\section{Present situation and development prospects of SESS}

Express is to delivery users' package rapidly by rail,road or air transportation. The characteristics of modern express is the point-to-point transport that is fast and convenient. In 2012 China express business was about 16 million, which is in the top three of the world. However, according to a survey of Chinese Association of trade in service customer service committee, many problems like not timely collection also emerged for the rapid development.[1]

In this study,college students who are fond of online shoppingand often use the self-service are chosen to be the target users. The SESS will have some functions such as self weighing,electronic payment etc. It can meet the demand of users in many aspects.Besides the SESS will be used in campus where the various kinds of public facilities are fully equipped because it is advantageous for the maintenance and promotion. 


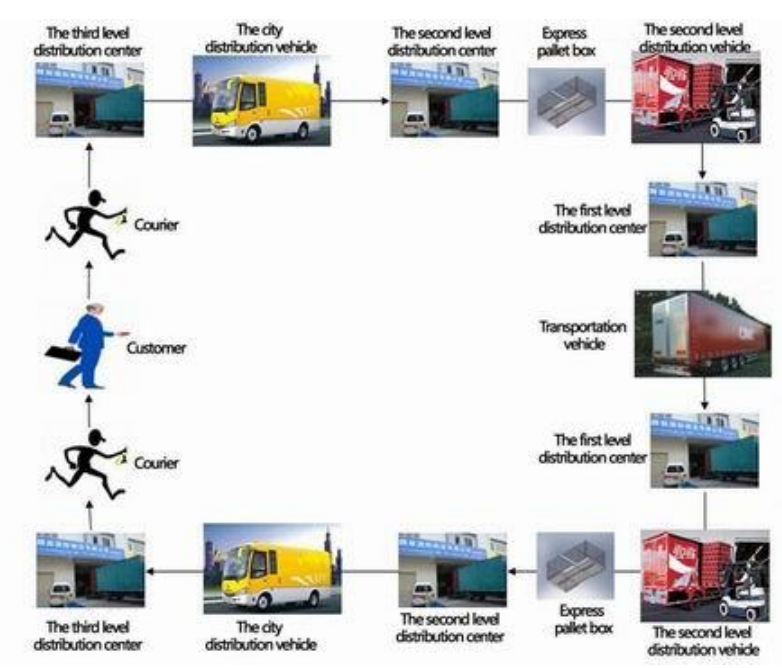

Figure 1:The mode operation of express

In fact,as early as in 1997,Singapore Post has launched the SAM and started the exploration of the self-help postal service mode.[2]Compared with the traditional express, the SESS has plenty of advantages. For the express companies, it can expand the parcel channels and package delivery network coverage;For the users, it can provide all day parcel posting and delivery service; For the express staff, it can reduce her workload;However,the SESS is in the initial stage. No matter in the University City ,the office building or the ordinary residential area,it will spread gradually and have a broad market prospect.[3]

\section{Overview of interactive interface design}

From the user perspective,interaction design studies how to make the products much more efficient and pleasant. Through the interaction design of product interface and users' behavior, an organic relationship between the product and its users can be established to achieve the user's goal effectively.And this is the purpose of interaction design. Interactive interface is a design categories which is produced from interaction design for the touch screen technology. It is a new media between human and machine relying on the touch screen.[4]The high-speed development of information technology makes the product functions numerous and complex. Besides some well-known product design such as Apple tend to be minimalism in product appearance design and the implementation of product functions relies more on the interactive interface design. If the interactive interface design is not good,these products can not achieve the users' needs and may cause some troubles. Therefore the interactive interface design of the SESS will follow the general guidelines, which can provide maximum autonomy and choice space to users .

\section{The interactive interface design of the SESS}

\section{The color analysis}

Color has an important significance in the interface design for the following reasons:

1.Color can serve as advertising. This is exactly why many companies will gradually establish their own standard color. For instance,red is the standard color of Coca Cola.

2. Color can be used to separate function section. The user's attention can be attracted to a particular element,especially when one color strongly contrasts with others,the effect is wonderful.

3. Color can remind users of the emotional resonance. Different colors tend to give users different psychological feelings. For example,red may make people feel enthusiastic while blue feels quiet and pure.[5]

In order to have a clear understanding of express industry, this paper will do the color analysis on 
the several express companies, which is shown in table 1 .

Table1:The color analysis for the website of express company

\begin{tabular}{|c|c|c|}
\hline Company & Website & Colour analysis \\
\hline DHL & 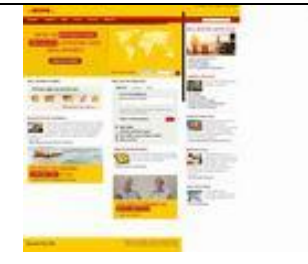 & $\begin{array}{l}\text { White background makes the page clear and clean. Bright yellow with } \\
\text { high reflective intensity is in the most part of interface, which exudes the } \\
\text { active,open and clear feeling. }\end{array}$ \\
\hline UPS & 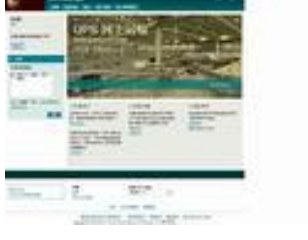 & $\begin{array}{l}\text { UPS website interface is mainly cyan,but there are some differences } \\
\text { in brightness and transparency.Cyan with high brightness as if add a lot of } \\
\text { light and can give users comfortable impression. That is what UPS wants } \\
\text { to convey to users. }\end{array}$ \\
\hline $\begin{array}{c}\text { ShunFeng } \\
\text { (SF) }\end{array}$ & 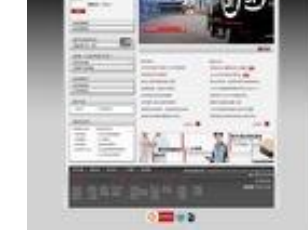 & $\begin{array}{l}\text { In } \mathrm{SF} \text { interface design silver and black are often used, which can give } \\
\text { users rational, mature, modern visual experience .Besides, grey has the } \\
\text { metal texture and can show the high-grade and elegant effect. }\end{array}$ \\
\hline EMS & 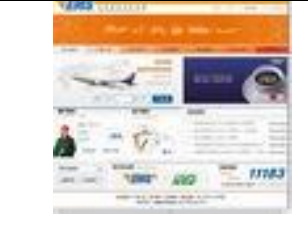 & $\begin{array}{l}\text { EMS is the only state-run express company in China. The most part of } \\
\text { website interface is orange. But in the menu bar the way of saturation } \\
\text { gradually increasing from left to right is used. }\end{array}$ \\
\hline $\begin{array}{c}\text { ZhaiJiSong } \\
\text { (ZJS) }\end{array}$ & 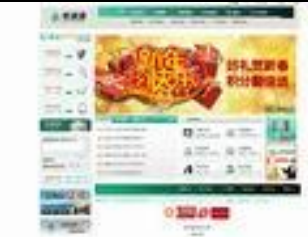 & $\begin{array}{l}\text { The main color of ZJS interface is the gradient from deep green to } \\
\text { dark green. Deep green often led to thoughts about coniferous forest rooted } \\
\text { in the land,which represents lean and straightforward impression. Color } \\
\text { gradually turning dark can bring the quiet and reserved feeling. }\end{array}$ \\
\hline
\end{tabular}

\section{Keywords and color association about the express industry.}

Before determining the interface color of SESS, we can summarize some key words and color association according to the general characteristics of express industry (Table2).For example,"safe,reliable,trust" can be associated to "guards,shield,protection,prevention,etc."Based on the color impression, we find that water blue,green and grey can convey the feeling of safety. [6][7] 
Table 2, The keywords of express and the colour association

\begin{tabular}{|c|c|c|c|}
\hline Keywords & Reason & Things association & $\begin{array}{c}\text { Colors } \\
\text { association }\end{array}$ \\
\hline $\begin{array}{l}\text { Safety, } \\
\text { reliability, } \\
\text { trust }\end{array}$ & $\begin{array}{l}\text { Customers wants their packages to } \\
\text { be sent to the destination safely and } \\
\text { intactly. Express stuff also hopes to } \\
\text { be trusted by customers. }\end{array}$ & $\begin{array}{l}\text { guardian,shield,protection,prevention,faith, } \\
\text { persistence,reassurance,package,hard } \\
\text { surface,fence,Protectivefilm,buffer,soft, } \\
\text { filler,wood,warm,etc. }\end{array}$ & \\
\hline $\begin{array}{c}\text { Warm, } \\
\text { durable, } \\
\text { simple }\end{array}$ & $\begin{array}{l}\text { The durable can not only saves the } \\
\text { material,but can save users time to } \\
\text { familiarize the newmachine. } \\
\text { Simplicity can them enjoy the using } \\
\text { process }\end{array}$ & $\begin{array}{l}\text { Wood,metal,stone,dusk, warm,colors,durabl } \\
\text { e,recycling,forever,solid,etc. }\end{array}$ & \\
\hline $\begin{array}{c}\text { Environmental } \\
\text { protection, } \\
\text { convenient }\end{array}$ & $\begin{array}{l}\text { The environmental protection } \\
\text { products can protect our home. The } \\
\text { material,locations,personnel } \\
\text { arrangement and the time of express } \\
\text { distribution all need to be } \\
\text { environmentally friendly. }\end{array}$ & 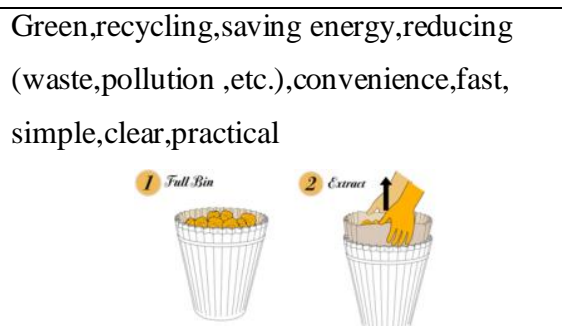 & \\
\hline Sense of speed & $\begin{array}{l}\text { The nature of express is to delivery } \\
\text { customers' packages to the } \\
\text { destination quickly and safely . } \\
\text { Therefore this product design should } \\
\text { have the sense of speed. }\end{array}$ & $\begin{array}{l}\text { Sportscar,tough,fashion,rapid,agile, } \\
\text { dexterity,strength,running,etc. }\end{array}$ & \\
\hline
\end{tabular}

Thus, in these color, the frequency of occurrence of blue,green, grey is the highest . It also shows they are closer to the theme of service system. They are chosen as the main color of SESS.

\section{The determination of the system operating process}

Whether the SESS can work relies on the interface guide and the users' operation. Therefore the operating process ,steps and prompts should be clear and concise in order to make the first use be very relaxed. Actually the task flow of SESS is the virtual results of manual working. So it should be consistent with the users' normal logic.In the general operating process, we should pay attention to:

1.KISS principle means"Keep It Simple Stupid.",which requires the Interface system to keep simple. So functional classification and nomenclature should be accurate and easy to understand.

\section{Login | Searching | Pick Up | Receiving Code | Enter Code | Take Package | Accept or reject}

Figure 2:The navigation bar of operating process

2.Usability. The system should display the most important function firstly to show the the focal point and relationship.Otherwise,too many functions may make the important ones be weakened.

3.Simplification. The operation steps and the interface jump level should be made as simple as possible.It can reduce the users' clicks and avoid misoperation.

4. Consistency. Module requires high consistency and similarity so as to reduce the learning cost and operation difficulty. 
5.Effectiveness. many people thinks that providing users with more choices means better.Take login as an example,users can login in through mang ways like mailbox, user name,mobile phone number and so on. But is it what users really expect? Actually too many choices may make users feel awkward. The best solution is to give users enough and the most effective choices. [4]

Based on the principles above,we determine the operation process of the system. It was shown in figure 6 .

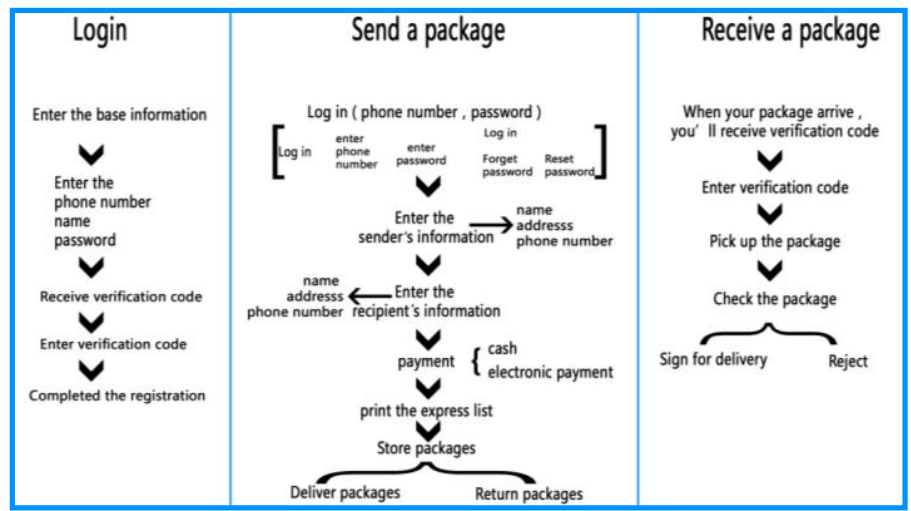

Figure 3: Interface process design of SESS

\section{The homepage framework and layout of the system interface}

After determining the operation process and main functions, the homepage framework and layout should be constructed. The logical interface layout enables users to grasp the information distribution and position key information quickly and accurately.Meanwhile,the homepage determines the structure of the system interface and the users'mental mode to the system operation. When we divide the function area of homepage, the main element combination such as "title","navigation" should be firstly determined;Secondly,the interface space should be divided in accordance to the functional requirements. Lastly,the function combination should be arranged to complete the whole construction.It is worth mentioning that the human visual habits is "from top to bottom,from left to right". Therefore,the function area must be arranged according to the importance and cognitive order.[8]

In order to determine the basic framework of homepage,the present ones need to be sorted,classified and analyzed.It's helpful for us to know their advantages and disadvantages. 
Table 3, The frame structure and features of interface

\begin{tabular}{|c|c|l|}
\hline layout & \multicolumn{1}{|c|}{ Feample } & \multicolumn{1}{c|}{ Features } \\
\hline matrix type & $\begin{array}{l}\text { The main icons are arranged on the page like lattice, which is } \\
\text { more flexible and free and has a strong sense of order. Thus it is } \\
\text { easy to identify and use. }\end{array}$ \\
\hline The left & $\begin{array}{l}\text { The title is at the top and the toolbar is on the left. The top-down } \\
\text { sort is intuitive and well organized. The structure is } \\
\text { compact,scientific and reasonable. From left to right,it gives } \\
\text { users navigation and then let them glance at the specific } \\
\text { information. }\end{array}$ \\
\hline down type & $\begin{array}{l}\text { Int is similar to the"left upper type" while it gives more emphasis } \\
\text { on the specific information.Most people are used to using the } \\
\text { right hand. The "right down type" can improve the user's } \\
\text { operation performance. }\end{array}$ \\
\hline type & $\begin{array}{l}\text { It can present plenty of information. The information showed } \\
\text { on the homepage need to be selected by customer;But too much } \\
\text { information makes the interface very dense. Overcrowded } \\
\text { display will also cause visual fatigue and receive error. }\end{array}$ \\
\hline
\end{tabular}

Above are the four frameworks and layouts that is typical in interactive interface design. Each has its advantages and disadvantages. They are applicable to different interaction devices. We can see that these four kinds of layout can distinguish the functional area clearly, which have high degree of identification. Therefore they are convenient for users to operate and widely used in interface design. However,interface with too much regularity may feel formated and rigid, which can not attract users' attention.How to balance the regularity and visual aesthetic feeling and then adding personalized form in the interactive interface design will be the key point of the framework construction of SESS. Based on the analysis above,the following two kinds of layout is determined:
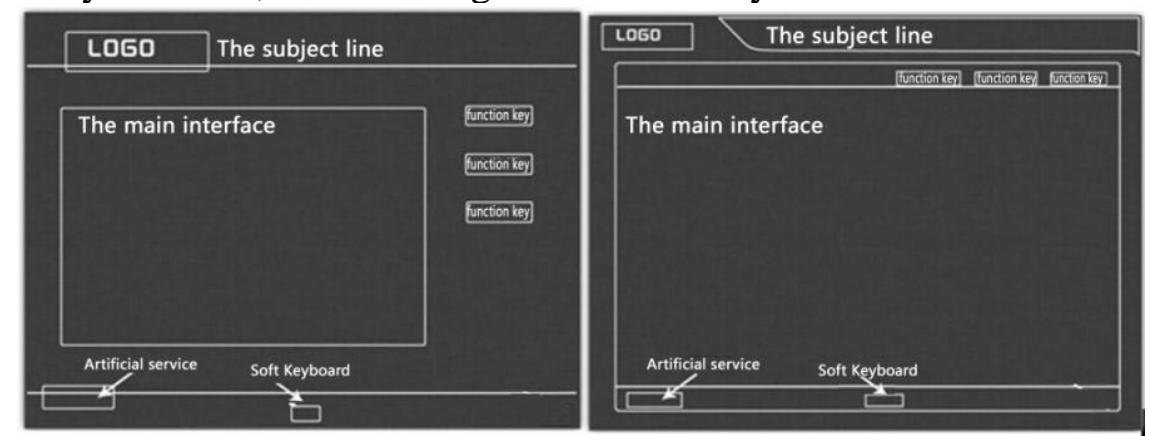

Figure 4:The basic framework of the system interface

\section{The visual image design of the system interface}

In the interface design, we determine the operation flow and interface structure. And we take two express companies:JZS and SF as the virtual object to do interface design.

In the interface design of ZJS SESS, blue is the main color. It can highlight the sense of modern technology with the reticulate pattern. The main operation buttons and company logo are green, which is very conspicuous and suitable for the background.In addition,the glittering and translucent green crystal button can not only play a decorative role throughout the interface,but also makes the picture much more vivid. The soft keyboard icon is located at the middle position below so that it can be 
clicked and used easily.Artificial service button is arranged at the lower left corner as many users are right-handed while artificial service is not commonly used.It can avoid the users' misoperation.

Most of SF SESS interface is black and grey, which hopes to highlight the feeling of steady and trustworthy. It can give more security to users.Besides we choose two kinds of crystal buttons:blue and transparent to distinguish the main functions and auxiliary functions; the arrangement of soft keyboard and artificial service button is the same as figure 5 .

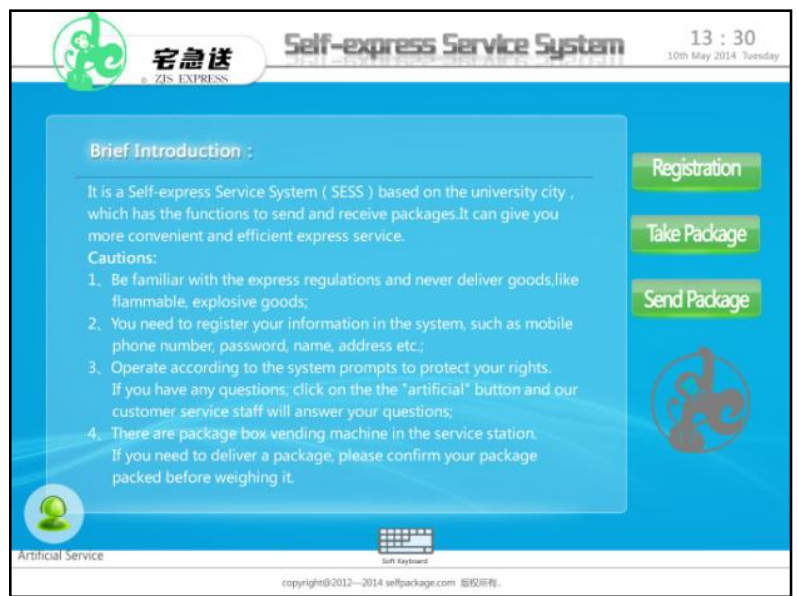

Figure 5: SESS interface for ZhaiJisong

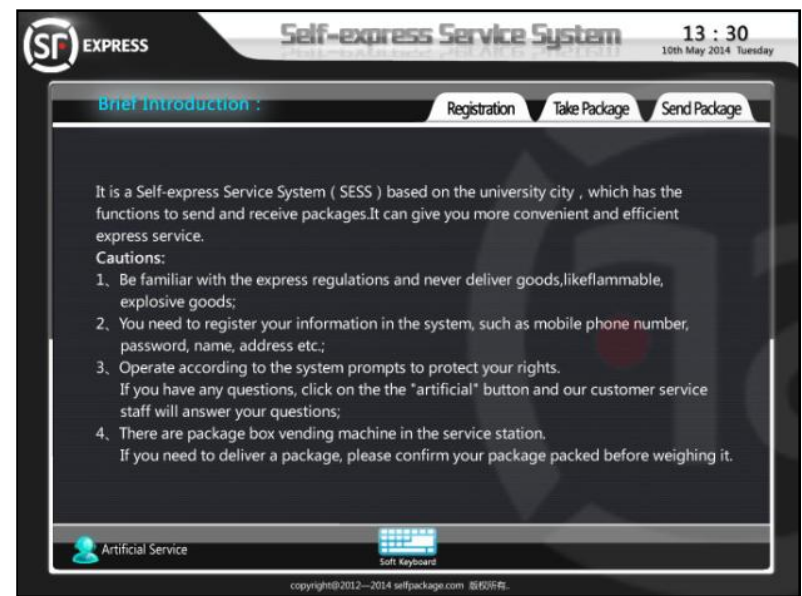

Figure 6: SESS interface for Shunfeng

\section{Conclusion}

Nowadays the self-service has spread in ATM,TVM and so on.Therefore, with the development of the express industry, growing numbers of people are willing to use express. And SESS also represents the general trend.There are self-sending,self-taking and vending equipments in the SESS.The operating system mainly provides service of registration,pick-up and sending. The interface design that has strong logic,simplified modules and high similarity, which allows users to complete the operation easily depending on the system instruction.

However,as a new industry, the interactive interface design of SESS still exists the following problems:It does not take cash on delivery into consideration;The distinction of main information and auxiliary information needs to be further improved in the system interface design;The system interface has not be tested in practice. In the future design research, we will continue to make up these shortcomings to let SESS improved and the application will be widespread.

\section{Acknowledgements}

This work was financially supported by "the Fundamental Research Funds for the Central Universities"(2013B34214)

\section{References}

[1]Wang Ping.A brief analysis on the management status and countermeasure of parcel service[J]. China Post, No.8.2003,P12 13

[2]He Li,Wei Dong. A restricted view at overseas self-service parcel posting system[J], China Post, No.12.2011,P62 63

[3]Zhang Shengru. Study on self service economy in E age[J].SCIENCE \& TECHNOLOGY INFORMATION. No.19.2008,P386 389

[4]Ren Kai. A study on interactive design of touch interface of Kiosks[D]. Shandong university 
Master's degree paper,2010

[5]Li Liangzhi,Zhang Mingyue,Huang He. The effects of color on Webpage interface design and The quantitative study[J]. Color application in Modern Asia:The fourth Asian color Forum, 2007 [6]Su Mi. Professional design and color[M]. Nanchang:Jiangxi Fine Arts Publishing House,2007 [7](Korea)Li Zaiwan (translated by Sun Yu). The designer 's opinion about the commercial color password (M) . Beijing: Publishing House of electronics industry,2007.

[8]Zhang Jiping. Human-computer interface design of self-service subway ticket machine[D].East China University Of Science and Technology Master's degree paper,2011 